\title{
O MUNICÍPIO E O ENIGMA DA COMPETÊNCIA COMUM CONSTITUCIONAL
}

\author{
José dos Santos Carvalho Filho'
}

Resumo: O presente estudo propõe-se a examinar alguns aspectos controvertidos a respeito do papel do Município numa das categorias previstas em nosso sistema de distribuição constitucional de poder - a competência comum do art. 23 da vigente Constituição. O Município, expressamente contemplado na competência comum, não é mero coadjuvante das demais pessoas federativas concorrentes, mas, ao contrário, reclama seja resguardada a sua autonomia e as decorrentes competências que o sistema lhe atribuiu.

Palavras-chave: competências constitucionais. Competência legislativa concorrente. O município na competência comum.

\section{INTRODUÇÃO}

A federação, do latim foedus (pacto, aliança), diversamente do sistema unitário, traduz uma forma plúrima de Estado por ser ele constituído de várias unidades federativas - uma representando o poder central e as demais os poderes regionais e locais. Daí ter como uma de suas características a descentralização política e administrativa, em que "o poder político é compartilhado entre a União e as unidades federadas", como consigna DALMO DALLARI. ${ }^{2}$

1 Mestre em Direito (UFRJ). Ex-Professor da UFF - Univ. Federal Fluminense (Curso de Pós-Graduação). Professor-palestrante da EMERJ - Escola da Magistratura do Estado do Rio de Janeiro.Membro do IBDA - Inst. Bras. de Direito Administrativo. Membro do IDAERJ - Inst. Dir.Administrativo do Estado do Rio de Janeiro. Procurador de Justiça do Estado do Rio de Janeiro (aposentado).Ex-Consultor Jurídico do Ministério Público do Estado do Rio de Janeiro. E-mail: josecarv@centroin.com.br

2 DALMO DALLARI, Elementos de Teoria Geral do Estado, Saraiva, 30ª ed., 2011, pág. 256. 
Origina-se da concepção americana como solução para ser criado um novo Estado, composto das várias colônias independentes que se radicaram na América em decorrência de conflitos religiosos com nações europeias, sobretudo com a Inglaterra. Nos Estados Unidos, porém, a federação nasceu por agregação, resultante da vinculação das colônias, que abdicaram de sua soberania para integrar um novo Estado - fato diverso do que sucedeu no Brasil, em que a federação se criou por desagregação, na qual províncias do Estado Imperial unitário adquiriram, com o advento da República, o poder de autonomia constitucional na medida em que se transformaram em Estados-membros do sistema.

O Estado federal apresenta-se marcado por diversas características, próprias desse regime, que não podem ser dissociadas de sua fisionomia específica. Uma delas é a "repartição constitucional de competências, isto é, a medida do poder político do Estado federal". ${ }^{3}$ Sendo forma composta de Estado, a federação não pode abrir mão da distribuição do poder entre a unidade central e as demais que integram o regime. Esse, aliás, é um dos grandes segredos do êxito do regime federativo adotado em vários países da modernidade. Variam as formas de distribuição do poder, mas não comentaremos o tema por refugir ao propósito deste estudo.

Nesta parte introdutória, não custa acrescentar um dado que a experiência tem mostrado a cada dia: não é tarefa simples a instituição do sistema de partilha de competências no cenário federativo. Assim como não é muito fácil instituir, também não o é colocá-lo em prática. Basta que haja distribuição do poder para haver a possibilidade de conflito entre as unidades federadas, e é exatamente em virtude desses conflitos que se faz necessária a criação de órgão judicial que possa dirimi-los.

Acresce que, se as dificuldades ressaltam nas federações de dois graus( ou esferas) de autonomia, como são aquelas formadas

3 GUILHERME PEÑA DE MORAES, Curso de Direito Constitucional, Atlas, $4^{\mathrm{a}}$ ed., 2012, pág. 333. 
apenas da União e de Estados (ou unidades com outra denominação, mas do mesmo feitio), imaginem-se, então, as complexidades que hão de resultar da federação de três graus, como é o caso do Brasil, no qual, além daquelas unidades, ainda figuram na federação os Municípios, com toda a autonomia própria das unidades integrantes do regime.

$\mathrm{O}$ presente estudo propõe-se a examinar alguns aspectos duvidosos (não todos, evidentemente) a respeito do papel do Município numa das categorias previstas em nosso sistema de distribuição constitucional de poder - a competência comum do art. 23 da vigente Constituição.

\section{COMPETÊNCIAS CONSTITUCIONAIS}

A um exame desavisado, parece singelo o sistema de partilha de competências adotado pela Constituição. Não o é, contudo, para aqueles que o analisam com maior acuidade e detença e que, por isso, vislumbram muitas questões de densa complexidade.

Embora possam variar as classificações entre os estudiosos, domina aquela que agrupa as competências em duas categorias - a competência legislativa e a competência material (ou administrativa). A primeira permite que o ente federativo edite leis e atos normativos fundados diretamente na Constituição, ao passo que a segunda o autoriza a criar "normas infraconstitucionais editadas em harmonia com o texto constitucional, através de um conjunto de ações concretas destinadas à satisfação do interesse público". ${ }^{4}$

A competência legislativa é a prevista nos arts. 22 ("Compete privativamente à União legislar sobre:..:") e 24 ("Compete à União, aos Estados e ao Distrito Federal legislar concorrentemente sobre:...”). A competência administrativa é contemplada nos arts. 21 (“Compete à União:...") e 23 ("É competência comum da União, dos Estados, do Distrito Federal e dos Municípios:...”).

4 PAULO ROBERTO DE FIGUEIREDO DANTAS, Curso de Direito Constitucional, Atlas, 2012, pág. 552. 
No confronto entre os dispositivos que cuidam das duas categorias de competências, é possível verificar alguns dados que não são compreensíveis de imediato e que demandam algum esforço do intérprete para obter a ratio constitutionis. De um lado, a competência comum do art. 23 é considerada administrativa por interpretação dedutiva, porquanto o Constituinte foi silente a respeito, só se referindo à competência para legislar. De outro, a competência legislativa do art. 24, embora se refira apenas à União, Estados e Distrito Federal, exclui estes dois últimos entes de algumas dessas competências, ao mesmo tempo em que, numa interpretação conjugada com o art. 30, certas competências são também exercidas pelos Municípios, estes não mencionados no dispositivo.

A própria classificação constitucional de competências legislativas e administrativas tem que ser interpretada cum grano salis. Primeiramente, não são rigorosamente excludentes. Depois, o ente que tem competência para legislar, terá que tê-la para administrar a matéria objeto da legislação. Por último, a competência administrativa pressupõe a capacidade de legislar, já que a Administração somente atua legitimamente sob o manto do princípio da legalidade. Daí o indiscutível acerto da observação de MANOEL GONÇALVES FERREIRA FILHO: "Com efeito, sendo a Administração sujeita ao princípio da legalidade, é evidente que a lei é que definirá a tarefa de cada um desses entes" ${ }_{5}$ Em outras palavras, a competência será delimitada por lei. ${ }^{6}$

Outro aspecto que tem dividido a opinião dos juristas é o que diz respeito à terminologia empregada pelo Constituinte para adjetivar a competência concomitante atribuída a mais de um ente federativo. No art. 22, a Constituição utiliza o advérbio concorrentemente, levando à inferência de que se trata de competência legislativa concorrente. Já no art. 23, preferiu-se o adjetivo comum, sendo então denominada de competência comum.

5 MANOEL GONÇALVES FERREIRA FILHO, Comentários à Constituição Brasileira de 1988, Saraiva, vol. 1, 1990, pág. 184.

6 PAULO NAPOLEÃO NOGUEIRA DA SILVA, Comentários à Constituição Federal de 1988, obra colet. coord. por Paulo Bonavides et alii, Gen-Forense, 2009, pág. 565. 
Alguns estudiosos distinguem a competência concorrente e a competência comum. Para CELSO RIBEIRO BASTOS, por exemplo, o entendimento é o seguinte: "Na competência concorrente, atuam sobre a mesma matéria, mas em campos diversos. $\mathrm{Na}$ comum atuam sobre a mesma matéria e nos mesmos campos sem conflito. A comum, por outro lado, é de atribuições, e a concorrente, legislativa". 7

Com a devida vênia, parece-nos inconsistente a linha demarcatória. Em nosso entender, pode haver conflitos na competência comum. ${ }^{8}$ Além do mais, não há coerência nem precisão em distinguir as competências com base na diferença de adjetivação, vale dizer, a comum seria própria da competência material e a concorrente o seria da competência legislativa. Quanto a este aspecto, seria de perguntar-se como seria a distinção se houvesse troca de adjetivos, passando o termo comum para a competência legislativa e o termo concorrente para a administrativa.

JOSÉ AFONSO DA SILVA dá o mesmo tom, entendendo que a competência comum (cumulativa ou paralela) é a que admite atuação conjunta de mais de uma entidade federativa, "sem que o exercício de uma venha a excluir a competência de outra", ao passo que na concorrente haveria primazia da União quanto às normas gerais, segundo os parágrafos do art. 24. ${ }^{9}$ A premissa de impossibilidade de exclusão também nos parece de duvidosa veracidade, já que é possível que haja conflito no exercício da competência comum, quando, por exemplo, houver legislação dissonante nos termos do art. 24. ${ }^{10}$

Sem embargo das tentativas de distinção, que mais dificultam a interpretação constitucional do que colaboram,

7 CELSO RIBEIRO BASTOS e IVES GANDRA MARTINS, Comentários à Constituição do Brasil, Saraiva, $3^{\circ}$ vol., Tomo I, 1992, pág. 374.

8 Os próprios autores, aliás, reconhecem a possibilidade de conflitos e apontam, como melhor solução, o critério da hierarquia, ou seja, exatamente o adotado para a competência concorrente do art. 24.

9 JOSÉ AFONSO DA SILVA, Direito Constitucional Positivo, Malheiros, $20^{\mathrm{a}}$ ed., 2002, pág. 479.

10 MANOEL GON ÇALVES FERREIRA FILHO, ob. e vol. cit., pág. 184. 
permitimo-nos entender que existem apenas duas categorias de competência no que diz respeito à participação dos entes federativos: ou se trata da competência privativa, se restrita a apenas um desses entes, ou da competência concorrente, quando participa mais de uma esfera federativa.

$\mathrm{O}$ adjetivo concorrente significa "que concorre, que coopera para o mesmo fim". ${ }^{11}$ Ora, se mais de um ente concorre para determinado fim na competência conjunta, é claro que tal competência é comum a todos os concorrentes. Lamentavelmente, o Constituinte decidiu usar dois vocábulos diversos nos arts. 23 e 24 para indicar o mesmo fenômeno competencial. O sentido de ambos, porém, é o mesmo. Se uma atividade é comum a várias pessoas, estas evidentemente concorrem para seu desempenho; e, se concorrem, é porque a atividade lhes é comum, como já assinalamos em outra oportunidade. ${ }^{12}$

Discute-se, ainda, sobre suposta diferença entre competência privativa e competência exclusiva. De acordo com clássica posição de JOSÉ AFONSO DA SILVA, a competência exclusiva não admite suplementariedade nem delegação, contrariamente ao que ocorre com a competência privativa, que permitiria tais situações. ${ }^{13}$

Apesar do grande respeito que nos merece o grande constitucionalista, a distinção parece inconsistente. Na verdade, privativo e exclusivo são termos sinônimos. Assim, se a competência é privativa para um ente federativo, é porque este tem exclusividade para exercê-la. Se numa hipótese há delegabilidade e na outra não há, melhor seria classificá-las em competência delegável e indelegável. Por tal motivo, vários autores não aceitam a referida classificação. ${ }^{14}$

11 CALDAS AULETE, Dicionário Contemporâneo da Língua Portuguesa, Delta, 1958, vol. I,, pág. 1.074.

12 JOSÉ DOS SANTOS CARVALHO FILHO, Manual de Direito Administrativo, Atlas, $25^{a}$ ed., 2012, pág. 327.

13 JOSÉ AFONSO DA SILVA, ob. cit., pág. 479.

14 Vide GILMAR FERREIRA MENDES et alii, Curso de Direito Constitucional, Saraiva, $4^{a}$ ed., 2009, pág. 873. Os autores apontam outros estudiosos com o mesmo pensamento, como Fernanda Dias Menezes de Almeida, Manoel Gonçalves Ferreira Filho, José Cretella Junior e Celso Bastos. 
Essa breve resenha teve apenas o intuito de salientar que o sistema de competências constitucionais nem sempre é de fácil interpretação, sobretudo diante de algumas dificuldades oriundas do texto, inclusive aquelas que concernem aos critérios de sua identificação.

\section{COMPETÊNCIA COMUM}

A competência comum, como a denomina a Constituição no art. 23, é aquela na qual se atribui a todos os entes federativos a execução de uma relação de atividades ou serviços, e, por essa razão, o dispositivo cuida da competência material, ou administrativa.

A ideia que inspirou a criação de uma competência conjunta de todos os entes federativos para certos serviços calcou-se, como bem afirma PINTO FERREIRA, no projeto de federalismo cooperativista, diante do qual as unidades da federação estariam associadas para a consecução de metas de interesse da coletividade e do próprio Estado. ${ }^{15}$

Reafirmando nossa posição, consideramos que para os serviços relacionados na competência comum concorrem todos os entes federativos mencionados no art. 23 , de modo que se trata efetivamente de competência administrativa concorrente.

Nesse concurso de unidades, todavia, não basta afirmar que a competência será exercida dentro de cada uma delas, como forma de impedir eventuais conflitos. Essa conclusão não poderia ser outra diante da circunstância de que todas elas devem observar seus próprios limites territoriais. O Estado, por exemplo, não tem competência para executar atividades no território de outro. O mesmo sucede com o Município.

A premissa dos limites territoriais de cada esfera integrante da competência comum, entretanto, nem sempre evita a ocorrência de conflitos. Alguns estudiosos chegam a sustentar que nessa competência não se levantam conflitos, mas, em nosso

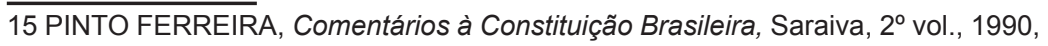
pág. 87. 
entender, eles podem surgir em determinadas atividades ou serviços. Podem não ser habituais, mas esse não é o problema: o problema é que há a possibilidade de posturas conflitantes entre as entidades competentes.

CELSO RIBEIRO BASTOS, por exemplo, ao comparar as competências comum e concorrente, confessa claramente: "Entendo, todavia, que, seja na competência comum, onde a ocorrência de conflito é menos provável, seja na competência concorrente, em que é mais provável,..." ${ }^{16} \mathrm{Na}$ dicção do saudoso constitucionalista, como se pode observar, ficou claro o reconhecimento dessa possibilidade - fato, aliás, que não é de estranhar no caso de pessoas políticas concorrentes para uma só atividade.

Justamente porque a competência comum, por ser concorrente, não pode ser analisada isoladamente, pela óbvia razão de que se trata de entidades de esferas diversas, os poderes dela derivados precisam ser interpretados em conjugação com outros elementos constitucionais relacionados à matéria de partilha de competências, e é nesse aspecto que sobreleva o exame da competência dos Municípios nesse tipo de concurso de entes para a prestação de serviços. Parece, pois, importante realçar a competência dos entes municipais diante de alguns enigmas da competência comum.

\section{COMPETÊNCIA LEGISLATIVA CONCORRENTE}

De plano, a aplicação da competência material comum do art. 23 da Constituição pressupõe a observância dos critérios definidores estabelecidos para a competência legislativa concorrente, prevista no art. 24.

fundamento - permitimo-nos insistir - reside no princípio da legalidade a que está sujeita toda a Administração Pública. Como esta não tem capacidade para inovar na ordem jurídica (ao menos por normas de base constitucional imediata),

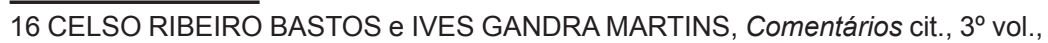
pág. 174. 
sua atuação reclama regulação legislativa, ainda que esta não tenha um detalhamento mais denso. O que lhe é vedado é a criação normativa primária, própria das leis e atos análogos, visto que sua tarefa consiste na ехесução dessas leis e atos.

Amolda-se, nesse aspecto, a clássica e precisa lição de HELY LOPES MEIRELES, hoje repetida praticamente por todos os autores: "Na Administração Pública não há liberdade nem vontade pessoal. Enquanto na administração particular é lícito fazer tudo que a lei não proíbe, na Administração Pública só é permitido fazer o que a lei autoriza. A lei para o particular significa 'pode fazer assim'; para o administrador público significa 'deve fazer assim' " 17 Na verdade, ninguém conseguiu explicar, numa síntese tão feliz, o parâmetro administrativo da legalidade.

Ora, se assim é, não se pode vislumbrar a hipótese de União, Estado, Distrito Federal ou Município exercerem sua competência material ou prestarem serviços sem que essa atuação esteja minimamente ancorada em regulação legal. Como podem eles cuidar da saúde e assistência pública (art. 23, II, CF) sem a lei disciplinadora ? Como poderiam fomentar a produção agropecuária e organizar o abastecimento alimentar (art. 23, VIII), sem a edição de suas leis ? E a política de educação para a segurança do trânsito (art. 23, XII) - como estabelecer e implementar sem a respectiva lei?

Temos observado que, em certas situações, entes federativos de uma esfera federativa menor se socorrem, para esses fins, de normatização elaborada por entes de esfera maior. Quando o fazem, abdicam inconstitucionalmente da competência que se lhes outorgou. Fazem-no por comodismo, ou por incompetência de seus governantes, mas essa postura é incondizente com a competência comum - na qual, ao serem delegados certos serviços a todos os entes federativos, restou implícita a suposição de que cada um deles editaria a respectiva lei reguladora.

17 HELY LOPES MEIRELLES, Direito Administrativo Brasileiro, Malheiros, 29a ed., 2004, pág. 88. 
A competência legislativa concorrente tem regras próprias para dirimir eventuais conflitos, o que não ocorre, ao menos expressamente, com a competência comum. Tais regras estão delineadas nos parágrafos do art. 24. A primeira delas é a de que a competência da União se limitará a estabelecer normas gerais (art. 24, § 1\%). Cuida-se de competência concorrente não cumulativa ou vertical, sendo destinada à União a edição de normas gerais. ${ }^{18}$ Há, pois, nesse critério uma garantia e uma restrição para a União: enquanto de um lado se lhe assegura competência privativa para editar as normas gerais, ao mesmo tempo impõe-se a ela a restrição no sentido de que pode exercer somente essa competência.

A segunda regra relaciona a União aos Estados - regra que, a nosso ver, traduz evidente emanação do primeiro critério: a competência da União para as normas gerais não exclui a competência suplementar dos Estados (art. 24, § 2०). Suplementar significa capaz de suprir, e o que é capaz de suprir logicamente complementa. "Pode o Estado, portanto, complementar a legislação nacional de normas gerais, isto é, editar normas que adicionem pormenores à regra primitiva nacional". ${ }^{19}$ A complementação normativa estadual, no entanto, sofre o influxo de alguns parâmetros, entre os quais o de que a lei estadual não pode inovar na ordem jurídica quando em confronto com a lei federal. Sem embargo de que a lei estadual, por revestir-se de caráter complementar, tenha sempre que inovar no direito positivo, a inovação só poderá dispor sobre matéria que atenda às suas peculiaridades, sem contrariar, todavia, o conteúdo da norma geral federal. ${ }^{20}$.

Outra regra é a do art. $24, \S 3^{\circ}$ : se não houver lei federal dispondo sobre normas gerais, podem os Estados exercer a competência legislativa plena, sempre para atender às suas peculiaridades. Na verdade, a competência jamais será rigorosamente plena, como o é a da União, pois que se sujeita a limitação mate-

18 ALEXANDRE DE MORAES, Direito Constitucional, Atlas, 12ª ed., 2002, pág. 298. 19 MANOEL GONÇALVES FERREIRA FILHO, Comentários cit., vol. 1, pág. 196. 20 MANOEL GONÇALVES FERREIRA FILHO, ob. e loc. cit. 
rial - a matéria tem que ser pertinente ao interesse do Estado - e territorial - a lei só valerá em seu território.

Esse critério se conjuga com o previsto no art. $24, \S 4$, da CF. Segundo esse dispositivo, a superveniência da lei federal sobre normas gerais suspende a eficácia da lei estadual no que lhe for contrário. De plano, é certo que, diante de tal critério, a lei estadual, no caso, terá inerente a si o caráter de temporariedade. A suspensão da eficácia não significa a revogação da lei estadual: não atinge a sua vigência, mas apenas os seus efeitos. Trata-se, porém, de situação anômala: a lei estadual existe e tem vigência, mas é despida de eficácia. Ou seja: é letra morta no direito positivo. De qualquer modo, com o advento da lei federal, surge o bloqueio da competência do Estado para editar normas gerais. ${ }^{21}$

Todos esses comentários servem para dar ênfase ao fato de que do sistema de competência legislativa concorrente é possível inferir, de um lado, que nem sempre haverá uma definição clara quanto à competência da União ou dos Estados. Há atividades situadas numa zona cinzenta, em cujo cenário podem surgir conflitos sobre o que constitui competência federal ou estadual (e distrital). Não tem sido incomum, por exemplo, que o Estado edite lei sobre matéria da competência da União, na suposição de que estaria legislando em caráter suplementar, como autoriza o art. 24, § 1ª da Constituição.

Numa outra vertente, cabe considerar que, embora não figure no texto do art. 24, caput, da CF, o Município também tem competência legislativa concorrente para diversos assuntos relacionados nos incisos do dispositivo. É certo que uma leitura apressada daquele mandamento poderia induzir em erro o intérprete, levando-o a supor que o Município estaria alijado da competência concorrente; seria mesmo uma interpretação equivocada. O papel legislativo do Município origina-se da interpretação harmonizada dos arts. 24 e 30 da Constituição - o que,

21 GILMAR FERREIRA MENDES, Curso cit., pág. 871. 
em algumas situações concretas, gera certa hesitação quanto aos marcos definidores da competência legislativa municipal.

Tendo em vista que a competência administrativa comum representa inegavelmente um corolário da competência legislativa concorrente, vale a pena tentar a demarcação da competência municipal no cenário das competências administrativas.

\section{MUNICÍPIO NA COMPETÊNCIA COMUM}

\section{a) Leis complementares de cooperação}

A despeito de ser a competência administrativa atribuída concorrentemente a todos os entes federativos, seria ingenuidade supor que seu exercício sempre fosse mobilizado por um processo harmônico e naturalmente cooperativo por parte das entidades competentes (embora fosse essa postura a se esperar de um povo civilizado).

Primo ictu oculi, nota-se que o Constituinte recorreu a um paradoxo: após enumerar no art. 23 todas as matérias da competência comum, previu, no parágrafo único do dispositivo, a edição de leis complementares destinadas à fixação de "normas para a cooperação entre a União e os Estados, o Distrito Federal e os Municípios, tendo em vista o equilíbrio do desenvolvimento e do bem-estar em âmbito nacional".

A rigor, seria de se indagar sobre a necessidade do dispositivo. Se houvesse consciência cívico-política entre os governantes dos entes federativos, nenhuma razão haveria para conferir à União o poder de estabelecer regras gerais de cooperação, pois que afinal esta nasce do consenso, e não de imposição. A competência outorgada à União demonstra claro intuito de verticalização, retirando aos demais entes a capacidade de sopesar regras contrárias a seus interesses.

O próprio Constituinte parece hesitar diante do que pretende com a lei complementar. Primitivamente, a previsão era da edição de uma lei complementar, mas a E.C. 53/2006 alterou o critério e passou a prever leis complementares. A plura- 
lização de tais diplomas, no entanto, não solveu as dúvidas que o dispositivo sempre suscitou. A expressão "equilíbrio do desenvolvimento e do bem-estar em âmbito nacional" não revela, com a mínima densidade, qual foi o objetivo da Carta. Com efeito, o sistema de partilha de competências em si já é o método pelo qual se busca o referido equilíbrio.

A crítica que fazemos ao dispositivo não é isolada e já foi apresentada por diversos estudiosos. MANOEL GONÇALVES FERREIRA FILHO, por exemplo, afirma que a previsão de lei complementar para regular a colaboração dos entes federativos "pouquíssimo contribuirá para a realização desse ideal, já que esta, efetivamente, é comandada ou limitada pelas regras de repartição de competência". ${ }^{22}$ A observação tem toda a procedência, porquanto o amoldamento da cooperação entre as unidades federativas nasce realmente do sistema de competências. Qualquer outra proposta de colaboração pode muito bem provir de negócios cooperativos, como os convênios e consórcios, prescindindo, pois, de normas de imposição.

CELSO RIBEIRO BASTOS endossa as críticas ao dispositivo, particularmente sobre o significado do objetivo constitucional. Diz o autor ser difícil entender o equilíbrio do desenvolvimento e do bem-estar, razão que o leva a ironizar a expressão: "Creio apenas ser difícil encontrar um 'desenvolvimento desequilibrado...' ".23 De fato, seriam as normas federais o instrumento idôneo a promover, mediante método vertical, o equilíbrio do desenvolvimento ? Qual é o sentido de "equilibrio do bem-estar" ?

O que se pode observar é que a própria União, a quem foi conferido o poder de legislar na hipótese, não tem editado as leis complementares a que se refere o dispositivo em comento. Se esse fato por si só não é suficiente para a inferência de que a norma é inócua ou inconveniente, não é menos verdadeiro que sugere, com certa ênfase, a resistência federal a esse dever de legislar, gerando, assim, o atual efeito omissivo.

22 Comentários cit., vol. 1, pág. 188.

23 Comentários cit., $3^{\circ}$ vol., pág. 430. 
Exatamente porque é nebuloso o sentido do art. 23, parágrafo único, cabe a Estados e Municípios adotar as cautelas idôneas à preservação de suas competências, a começar pela competência legislativa atribuída a cada uma das esferas da federação.

Resulta, pois, que nenhuma lei complementar prevista no art. 23, parágrafo único, da Constituição, poderá conter qualquer norma que, a pretexto de disciplinar a cooperação entre as pessoas federativas, vulnere a competência privativa do Município para dispor sobre assuntos de interesse local (art. 30, I, CF). Tal competência simboliza a autonomia municipal, não podendo ser afetada por lei de qualquer outra esfera federativa, pena de incidir em flagrante inconstitucionalidade.

\section{b) Predominância do interesse}

É mister trazer à tona o entendimento de que, na ocorrência de conflito quanto à instituição e execução da atividade administrativa, deva o intérprete socorrer-se do critério vertical, ou hierárquico, dando-se prevalência à União. ${ }^{24}$ Semelhante é o entendimento segundo o qual, reconhecido o critério da predominância do interesse, é de admitir-se uma hierarquia de interesses, em que os entes mais amplos preferem aos mais restritos. ${ }^{25}$

Em nosso entender, tal critério não é imediato nem pode ser empregado indistintamente e, dependendo da hipótese, pode ser marcado por inconstitucionalidade.

No que toca ao Município, há de prevalecer o critério da predominância do interesse, que não se coaduna com a hierarquia de interesses, considerando a extensão dos entes federativos. Ao contrário, o interesse predominante não coincide sempre com o interesse hierárquico, visto que leva em conta a competência da unidade federativa, e não a sua extensão.

Desse modo, sendo o serviço comum, se o interesse a preponderar for o nacional, a competência será da União, com

24 Nesse sentido, CELSO RIBEIRO BASTOS, Comentários cit., $3^{\circ}$ vol., pág. 374. 25 GILMAR FERREIRA MENDES, ob. cit., pág. 870 
exclusão das demais entidades federativas. Mas poderá predominar o interesse regional, quando então a competência será do Estado. Caso haja predominância do interesse local, a competência será do Município, com exclusão das outras esferas federativas. ${ }^{26}$

Parece-nos, portanto, que a preservação da autonomia do Município não se pode extrair do art. 23, nem de seu parágrafo único, mas sim dos incisos I e II do art. 30, que lhe asseguram tanto a competência para legislar sobre assuntos de interesse local, quanto a de suplementar a legislação federal e estadual, no que couber. Esse critério, que dá caráter exclusivo à competência municipal, não pode ser atingido nem pela lei complementar federal ou por lei estadual, nem por qualquer ato administrativo de organização que não emane da autoridade municipal.

Significa que, em caso de identidade de serviço administrativo, não pode ser adotado, de plano, o critério vertical, atribuindo-se competência ao ente maior. É preciso interpretar o sistema conjugando-se as competências administrativa e legislativa para chegar-se à entidade que tem competência privativa para legislar. Coincidindo um serviço estadual e um municipal, por exemplo, deverá ser resguardada a competência do Município no caso de atividade de interesse local, pois que é exatamente esse fator que gera a predominância do interesse municipal.

Consequentemente, sob essa ótica não se pode afirmar, a priori, que alguma atividade inserida na competência comum do art. 23 possa excluir os demais entes federativos, se se tratar de interesse propriamente conexo a alguma esfera. No caso do Município, a atividade de interesse local pode ser concorrente no caso de interesses regional e nacional, mas estes jamais poderão alijar o ente municipal dessa mesma atividade.

26 É a opinião de HELY LOPES MEIRELLES, Direito Administrativo cit., pág. 331, e JOSÉ AFONSO DA SILVA, Direito Constitucional cit., pág. 476. 


\section{c) Serviços locais}

A Constituição não se limitou a garantir ao Município a competência para legislar sobre assuntos de interesse local (art. 39, I) e de suplementar a legislação federal e estadual (art. 30, II). Previu também algumas competências para a organização e prestação de serviços públicos de interesse local, reforçando a competência privativa contemplada no inciso I do art. 30 .

A título de exemplo, lembre-se o inciso $\mathrm{V}$ do mesmo art. 30, que confere ao Município competência para "organizar e prestar, diretamente ou sob regime de concessão ou permissão, os serviços públicos de interesse local, incluido o de transporte coletivo, que tem caráter essencial". Outro exemplo significativo é o do inciso VIII, que dispõe: "promover a proteção do patrimônio histórico-cultural local, observada a legislação e a ação fiscalizadora federal e estadual”.

Não há dúvida de que, no cenário da partilha de competências, a Constituição não relegou o Município à condição de simples partícipe do regime federativo, nem tampouco ao status de entidade menor subordinada à União e ao Estado. No sistema adotado, é possível verificar, numa interpretação global, que certas competências municipais são intangíveis e até mesmo se sobrepõem às das outras pessoas políticas, quando se trata de exclusividade da competência. Assim, ao referir-se aos serviços locais, a Constituição, como observa ALEXANDRE DE MORAES, foi além da fórmula genérica do interesse local, prevista no art. 30, I. ${ }^{27}$

A competência do Município para a organização dos serviços locais cabe exclusivamente a ele, tanto quanto lhe cabe, da mesma forma, fixar a estrutura, projetar as diretrizes e adequar a prestação dos referidos serviços. Na correta advertência de MANOEL GONÇALVES FERREIRA FILHO, " $a$ liberdade na organização desses serviços está no cerne da autonomia municipal tal qual a garante a Constituição federal. Dessa forma, não parece lícito ao Estado federado reduzi-la". ${ }^{28}$ Tampouco à União,

27 ALEXANDRE DE MORAES, Direito Constitucional cit., pág. 290.

28 Comentários cit., vol. 1, pág. 220. 
acrescentamos nós, porquanto a salvaguarda da autonomia não pode ser atingida por qualquer outra unidade federativa.

É sempre cabível sublinhar que a competência administrativa não subsiste sem a retaguarda da competência legislativa: esta é a competência fundamental e originária, ao passo que aquela é a competência subsidiária e derivada. A nenhum ente federativo será lícito exercer sua competência material (ou administrativa) sem que, previamente, lhe tenha sido outorgada a respectiva competência legislativa. Essa é a regra básica do sistema de repartição de competências vigente na Constituição.

Desse modo, na competência comum do art. 23, o Município jamais poderá ser descartado por qualquer outra entidade federativa, se o exercício da atividade administrativa se tiver fundado em sua competência legislativa. Por esse motivo, não parece correto afirmar que, no caso de conflito, deva prevalecer a entidade de maior extensão, entendimento esse que desconsidera inteiramente o critério da predominância do interesse.

Conquanto pareça singelo identificar essa linha demarcatória, na prática tem havido conflitos sobre a matéria, obrigando, inclusive, à edição de súmulas pelos Tribunais superiores. Para exemplificar: a fixação do horário local para o comércio é da competência municipal, conforme assentado na Súmula no 645 do STF. ${ }^{29}$ Todavia, foi reconhecida a competência da União para dispor sobre horário de instituições bancárias. ${ }^{30}$ Já a questão do tempo de espera em fila de banco foi incluída na competência do Município, argumentando-se com a proteção ao consumidor. ${ }^{31}$ A fixação da distância entre farmácias foi, durante algum tempo, considerada de interesse local e da competência do Município, mas, posteriormente, julgou-se que a restrição ofendia o princípio da livre concorrência, matéria da competência federal. ${ }^{32}$

29 Súmula 645: "É competente o Município para fixar o horário de funcionamento de estabelecimento comercial".

30 STF, RE 130.683, DJ de 09.10.92, e Súmula 19, STJ. .

31 STF, RE 432.789, DJ de 07.10.2005.

32 STF, Súmula 646: "Ofende o princípio da livre concorrência Lei municipal que impede a instalação de estabelecimentos comerciais do mesmo ramo em determinada área." 
As questões recorrentes em matéria de competência estão a demonstrar que nem sempre é fácil atribuir a competência correta à entidade federativa. No caso do Município, como a competência comum encerra a presença de vários serviços de interesse local, tais serviços serão da competência municipal, estando, assim, vedado ao Estado e à União legislar sobre o serviço, bom como organizá-lo e prestá-lo nas comunidades. Daí a relevância de identificar a atividade de interesse local, como assevera a Constituição. ${ }^{33}$

\section{CONCLUSÃO}

Diante de todas essas breves considerações, impõe-se concluir.

O objetivo a que se preordenou este sucinto estudo foi apenas o de reafirmar a conclusão a que já chegaram diversos estudiosos - qual seja a de que o sistema de repartição de competências apresenta fundas complexidades, sobretudo quando se trata de uma federação de três graus, como a brasileira.

No exame do sistema, a competência comum, prevista no art. 23 da Constituição, e que, na verdade, traduz uma competência administrativa concorrente, oferece certos enigmas, ou seja, certas dificuldades de interpretação, a começar pelo fato de que essa competência pressupõe a capacidade legislativa, objeto de outra competência - a competência legislativa concorrente.

As dificuldades se estendem ao parágrafo único do mesmo art. 23, que prevê a edição de leis complementares de regulação das formas de cooperação dos entes federativos - o que parece inócuo, pela falta de consistência, e inadequado, pelo descompasso entre cooperação e imposição, isso sem contar com os instrumentos apropriados para a cooperação, como os convênios e consórcios, autorizados pelo art. 241 da Constituição.

Como em toda a competência concorrente, podem surgir conflitos entre as entidades em concurso, tanto posi-

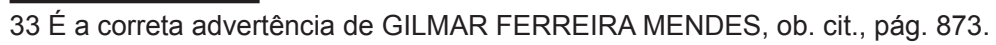


tivos, quando mais de uma se julga competente para determinada atividade, quanto negativos, quando cada uma renega a competência que se lhe atribuiu. E tais conflitos podem ocorrer também na competência comum.

O deslinde desses conflitos não pode fundar-se no critério hierárquico ou vertical, em que preleva a entidade de maior extensão. $\mathrm{O}$ critério adequado há de levar em consideração a predominância do interesse, que deve ser conjugado com outros critérios adotados dentro do próprio cenário do sistema de partilha de competências.

O Município, expressamente contemplado na competência comum, não é mero coadjuvante das demais pessoas federativas concorrentes, mas, ao contrário, reclama seja resguardada a sua autonomia e as decorrentes competências que o sistema lhe atribuiu. Por isso, a lei complementar prevista no art. 23, parágrafo único, não pode vulnerar as competências do Município a pretexto de estabelecer normas de cooperação.

Por outro lado, o critério da predominância do interesse, associado ao do interesse local e ao dos serviços locais, assegura ao Município a manutenção de sua autonomia e de suas prerrogativas, sendo inviável adotar posições generalistas que visem a excluir a competência municipal, quando o correto é a cuidadosa análise da situação concreta que permita identificar a verdadeira linha demarcatória da competência.

Em suma, o que se quer consignar é que os eventuais enigmas que tornam sombria a competência comum, ou administrativa concorrente, não podem deixar de considerar a autonomia que o Município recebeu da Constituição, nem as competências que esta lhe atribuiu.

Abstract: This study will examine some controversial aspects regarding the role of Municipalities in one of the categories established in our constitutional competence distribution system, specifically the common competence referred to in art. 23 of the Constitution in effect. Municipalities, which 
are explicitly covered in the shared competence, are not mere coadjutants of the other entities of the federation; to the contrary, their autonomy and the resulting competences attributed by the system should be safeguarded.

Keywords: Constitutional competencies; Concurrent legislative competence; Municipalities in common competence.

\section{REFERÊNCIAS}

BASTOS, Celso Ribeiro e MARTINS, Ives Gandra, Comentários à Constituição do Brasil, Saraiva, 3º vol., Tomo I, 1992.

CALDAS AUlETE, Dicionário Contemporâneo da Lingua Portuguesa, Delta, RJ, 1958, vol. I.

CARVALHO FILHO, José dos Santos, Manual de Direito Administrativo, Atlas, 25a ed., 2012.

DALLARI, Dalmo, Elementos de Teoria Geral do Estado, Saraiva, 30a ed., 2011.

DANTAS, Paulo Roberto de Figueiredo, Curso de Direito Constitucional, Atlas, 2012.

FERREIRA, Pinto, Comentários à Constituição Brasileira, Saraiva, 2º vol., 1990.

FERREIRA FILHO, Manoel Gonçalves, Comentários à Constituição Brasileira de 1988, Saraiva, vol. 1, 1990.

MEIRELLES, Hely Lopes, Direito Administrativo Brasileiro, Malheiros, 29a ed., 2004.

MENDES, Gilmar Ferreira et alii, Curso de Direito Constitucional, Saraiva, $4^{\mathrm{a}}$ ed., 2009..

MORAES, Alexandre de, Direito Constitucional, Atlas, 12a ed., 2002.

MORAES, Guilherme Peña de, Curso de Direito Constitucional, Atlas, $4^{a}$ ed., 2012.

SILVA, José Afonso da, Direito Constitucional Positivo, Malheiros, 20ª ed., 2002.

SILVA, Paulo Napoleão Nogueira da, Comentários à Constituição Federal de 1988, obra colet. coord. por Paulo Bonavides et alii, Gen-Forense, 2009. 